\title{
Comprehensive Study on Gate Driver for SiC-MOSFETs with Gate Boost
}

\author{
Koji Yamaguchi*a) $^{*}$ Member, \\ Kenshiro Katsura* \\ Non-member \\ Tatsuro Yamada* Non-member, Yukihiko Sato ${ }^{* *}$ Senior Member
}

(Manuscript received March 8, 2017, revised Nov. 14, 2017)

\begin{abstract}
This paper presents a high-speed, low loss, and low noise gate driver for silicon-carbide ( $\mathrm{SiC}$ ) MOSFETs. We propose a gate boost circuit to reduce the switching loss and delay time without increasing the switching noise. The proposed gate driver enables converter-level efficiency improvements or power density enhancements. SiC MOSFETs have attracted significant interest as the next generation power devices. In general, the switching performance of power devices exhibits a trade-off between switching loss and noise. SiC-MOSFETs are expected to switch faster than Silicon IGBTs; however, faster switching might cause switching noise problems such as unwanted electromagnetic interferences (EMI). In this paper, we propose a gate driver topology that improves the switching performance of SiC-MOSFETs, and confirm the reduction in switching loss and delay time through experimental results.
\end{abstract}

Keywords: gate drive, EMI, inverter, $\mathrm{SiC}$, MOSFET, switching loss, switching noise

\section{Introduction}

This paper presents a gate driver topology designed for silicon-carbide ( $\mathrm{SiC}$ ) MOSFETs to achieve higher speed, lower loss, and lower noise than conventional gate drivers. We proposed a gate boost circuit to reduce the switching losses and delay time, without increasing the switching noise. The proposed gate driver enables converter-level efficiency improvements and/or power density enhancements.

Various novel gate drive technologies are summarized in (1). Recently developed SiC-based power converters achieved higher power density than silicon-based power converters $^{(2)-(4)}$. SiC-MOSFETs have lower losses and faster switching capability than silicon ( $\mathrm{Si}$ ) insulated gate bipolar transistors (IGBT). Lower losses in power converters enable power density enhancements by using smaller cooling systems. Higher switching frequency also enables higher power density by using smaller passive components.

It is widely known that there is a trade-off between switching loss and noise. Decreasing gate resistor value is a simple method to reduce switching loss and delay time, but it might cause higher switching noise, such as voltage overshoot and ringing, leading to electromagnetic-interference (EMI). In contrast, increasing gate resistor value reduces the switching noise, but switching loss and delay time increase. These conventional gate drivers just result in acceptable compromise between switching losses and noise. Improving the tread-off of switching is crucial to improve performances of

a) Correspondence to: Koji Yamaguchi. E-mail: koji_yamaguchi@ ihi.co.jp

* Department Electrical System, Product Development Center, IHI Corporation

1, Shin-Nakahara-cho, Isogo-ku, Yokohama 235-8501, Japan

${ }^{* *}$ Department Electrical and Electronic Engineering, Chiba University

1-33, Yayoi-cho, Inage-ku, Chiba 263-8522, Japan power converters and enhance power density.

Evaluation and analysis have been performed in terms of switching characteristics ${ }^{(5)-(10)}$. The trade-off between switching loss and EMI is comprehensively evaluated in (5). The impact of temperature and switching rate of $\mathrm{SiC}$ devices on their performance is evaluated in (7). Switching characteristics of novel high voltage SiC-MOSFETs and SiC-IGBTs are evaluated in (9). Impacts of anti-parallel SiC-SchottkyDiodes on switching characteristics are evaluated in (10).

Some gate driver topologies have been proposed to improve the switching performances of Si IGBTs, such as active gate control methods or soft gate methods as in (11)-(14). The soft gate method also applies to hybrid SiC devices, as shown in (15). A d $V / \mathrm{d} t$ control method is proposed for SiCJFET with cascode silicon MOSFETs in (16). Novel active gate drivers for SiC-MOSFETs are proposed in (17)-(24). As SiC-MOSFETs have lower gate threshold and withstand less negative gate voltage, novel gate drivers to reduce negative voltage spike are introduced in (17) (18). A closed-loop feedback control gate driver is proposed in (22). High resolution programmable gate drivers are proposed in (23) (24). These drivers are usually implemented using customized integrated circuits (ICs) which need more cost.

The authors of this paper previously introduced a low switching loss gate driver in (25). We also presented further experimental results evaluating the switching noise of the proposed gate drivers in (26). This paper presents comprehensive evaluation results, detailed explanations, and design tips for the proposed gate driver as a simple, easy to implement, and cost-effective solution to improve the switching performance of SiC-MOSFETs. The proposed gate driver can be implemented with just few chip resistors, chip capacitors, and small transistors.

The purpose of this research is to reduce the switching loss and delay time of SiC-MOSFETs without increasing the switching noise. 
In section 2, we show the principle and design methods of the proposed gate driver. In section 3, we present the experimental results evaluating the switching characteristics of SiC-MOSFET with the proposed gate driver which confirmed that the proposed gate driver improves the trade-off of switching. Section 4 presents the experimental results on a SiC-MOSFETs inverter using the proposed gate driver. Section 5 gives the conclusion of this paper.

\section{The Proposed Gate Driver for SiC-MOSFETs}

2.1 The Proposed Gate Driver Concept Figure 1 shows the proposed gate driver. Figure 2 shows the conventional gate driver for comparison. Figure 3 shows example of the active gate drive method concept.

The active gate drive methods are very effective to improve the power devices' switching performance. In contrast, the

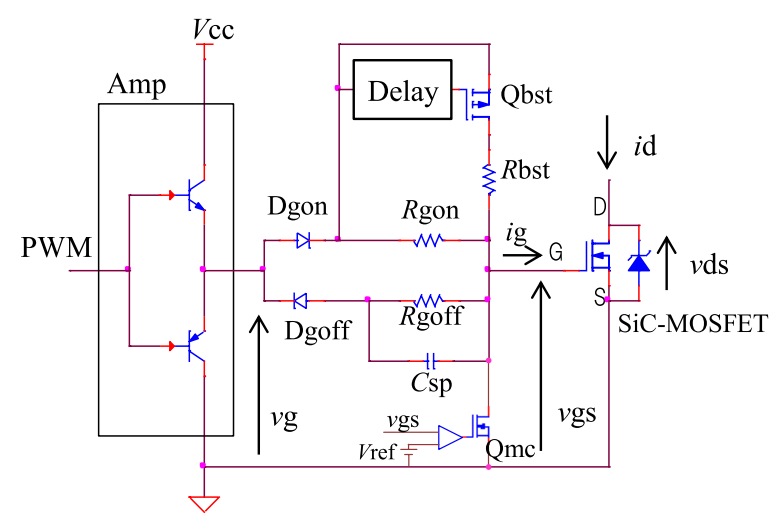

Fig. 1. Proposed gate driver schematic diagram

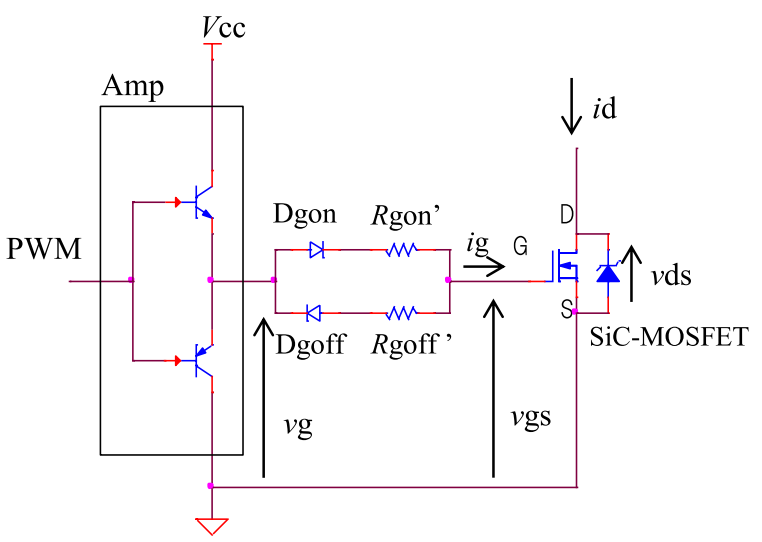

Fig. 2. Conventional gate driver schematic diagram

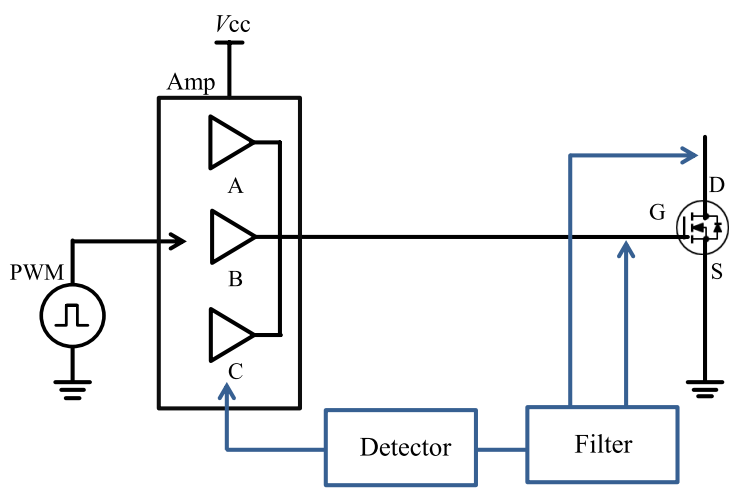

Fig. 3. Conceptual example of active gate drive methods active gate drivers are usually implemented using customized ICs, so might need more costs than conventional gate drivers. Typical active gate drivers have gate or drain voltage detectors for monitoring the switching process, then switch gate driver circuits to optimize the gate drivers' output impedance. Thus, the active gate drivers might have some risk of fault detection, owing to the switching noise such as switching surge, oscillation, and fast switching transient of SiC devices.

For this reason, the active gate drivers need low-pass filters to avoid the fault detection, but time delay caused by the filters might not meet the requirements associated to the fast switching capability of SiC devices.

The proposed gate driver uses a gate boost circuit to enhance turn-on characteristics and a speed-up capacitor for faster discharge of SiC-MOSFET gate during turn-off. The gate boost circuit is implemented using a small number of components as resistors, capacitors, and transistors. The proposed gate driver does not use detectors and filters, being less prone to malfunction than the active gate drivers, also meeting the fast switching requirements associated with $\mathrm{SiC}$ MOSFETs. The proposed gate driver improves switching performance in a simple and cost-effective manner.

2.2 Turn-on Procedure of the Proposed Gate Driver

Figures 4 and Fig. 5 illustrate the turn-on procedure of the proposed gate driver, Fig. 5 depicting waveforms in a leg configuration with inductive load as further shown in Fig. 12.

Once PWM signal turns high which means command to turn on the SiC-MOSFET, the Amp output $v$ g goes up to $V \mathrm{cc}$ level and $i g$ begins to flow and charge the SiC-MOSFET gate through Dgon and Rgon. When $v$ gs becomes higher than the gate threshold voltage $V$ th, the drain current $i$ d starts to flow and goes up. During current commutation from the high side to the low side, the high-side diode is still on, there for $v \mathrm{ds}$ change only voltage change of the high-side diode and stray factors as $i \mathrm{~d}$ and $i \mathrm{~F}$ change. When the drain current $i \mathrm{~d}$ reaches the load current, the drain voltage $v$ ds starts decreasing significantly because the high-side diode turned off.

The gate boost circuit is activated after a delay time $t \mathrm{dbst}$, the boost switch Qbst turns on and gate boost current igbst flow through Dgon, Qbst, Rbst to charge the SiC-MOSFET gate faster than the conventional gate drive methods. Since the boost current igbst push up $v$ gs, the drain voltage $v$ ds and on-state resistance of the SiC-MOSFET decrease faster than that in the conventional gate drive methods. Thus, the proposed gate driver is able to reduce the turn-on loss and time. The delay time $t$ dbst must be set to a proper value to ensure that the boost switch Qbst turns on after the drain current $i \mathrm{~d}$ reaches its peak current. The proposed gate driver applies a lower current in the beginning of the turn-on process to avoid producing a high switching noise, then boost up the gate drive after drain current transient to reduce faster the switching loss and on-state resistance of the SiC-MOSFETs.

2.3 Turn-off Procedure of the Proposed Gate Driver Figures 6 and Fig. 7 illustrate the turn-off procedure of the proposed gate driver.

The proposed gate driver uses a speed-up capacitor to reduce the turn-off delay time. At the beginning of the turnoff sequence, the speed-up capacitor $C$ sp quickly discharges the SiC-MOSFET gate to reduce the switching delay time. Subsequently, the proposed gate driver slowly discharges the 


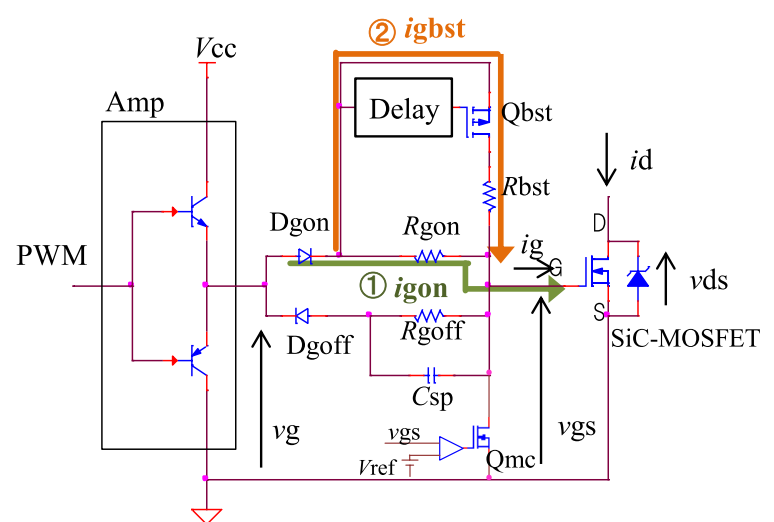

Fig. 4. Gate current flow diagram for the proposed gate driver at turn-on

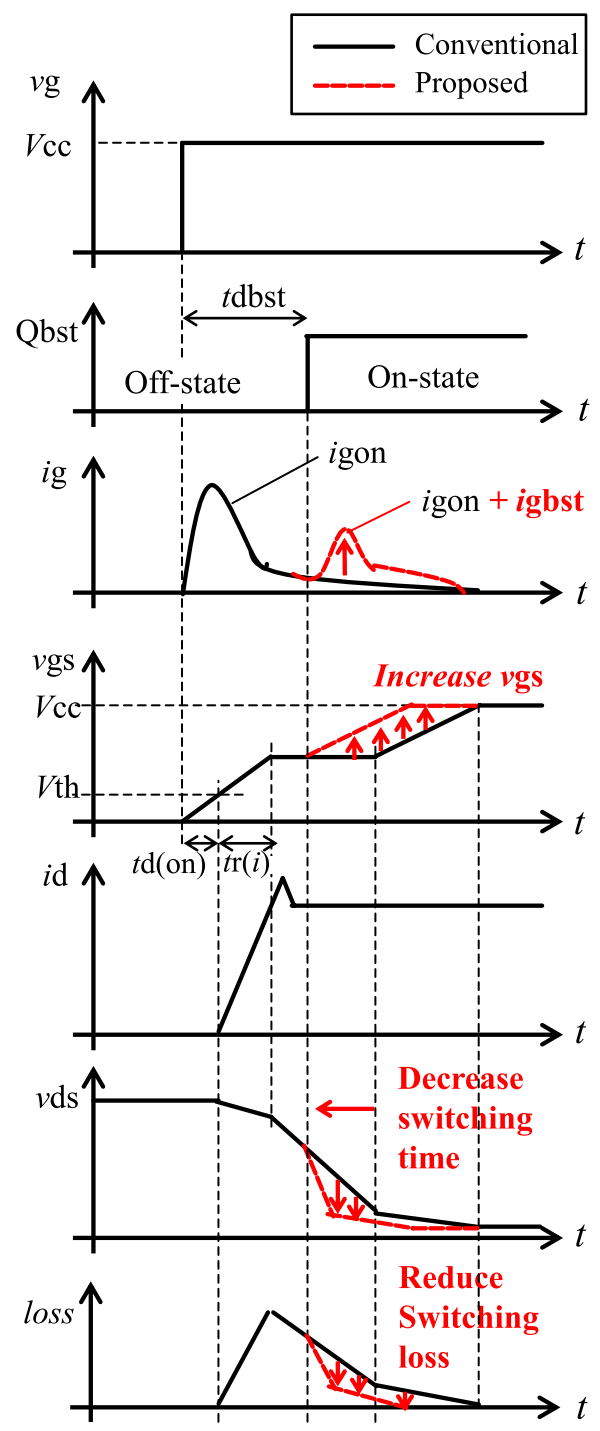

Fig. 5. Turn-on procedure of the proposed gate driver

SiC-MOSFET gate via Rgoff but only after the gate voltage $v$ gs decreases below $V \mathrm{ml}$ to avoid producing a larger voltage overshoot. After vgs decreases below $V$ th, the switch Qmc turns on to keep the SiC-MOSFET turned off safely.

2.4 Proposed Gate Driver Design Method This section introduces the design process and methods for the proposed gate driver. Figure 8 shows an example schematic of

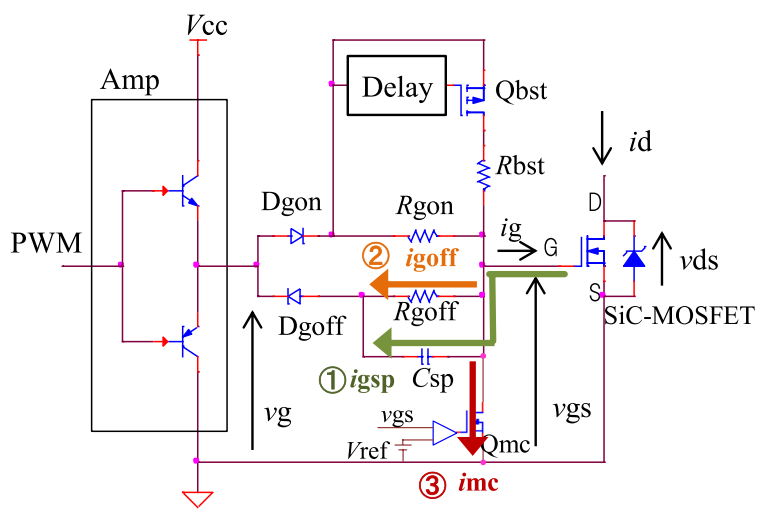

Fig. 6. Gate current flow diagram for the proposed gate driver at turn-off

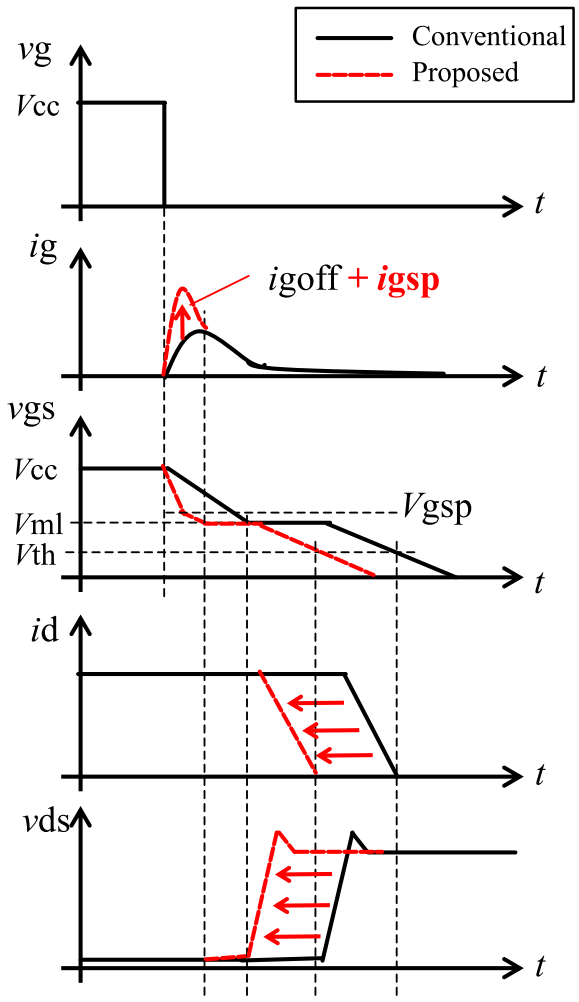

Fig. 7. Turn-off procedure of the proposed gate driver

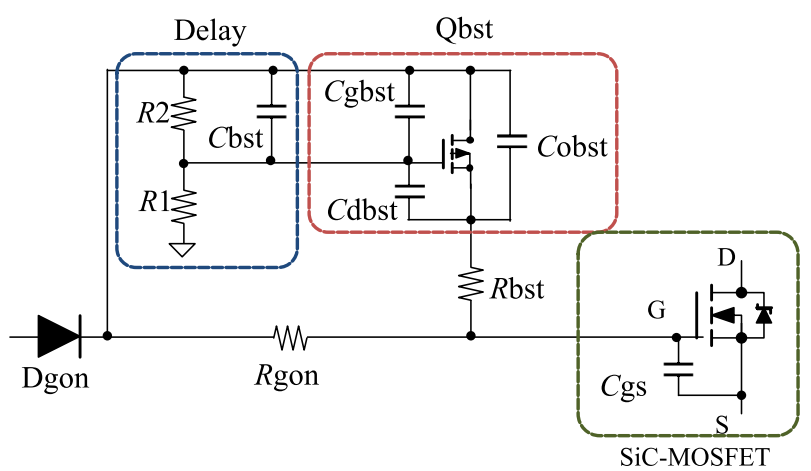

Fig. 8. Gate boost circuit schematic example

the gate boost circuit. The delay circuit consists of resistors $R 1, R 2$, and capacitor $C$ bst. Figure 8 shows the parasitic capacitances of Qbst such as $C$ gbst, $C$ dbst, and Cobst. It also shows the SiC-MOSFET's gate capacitance $C$ gs. The time 


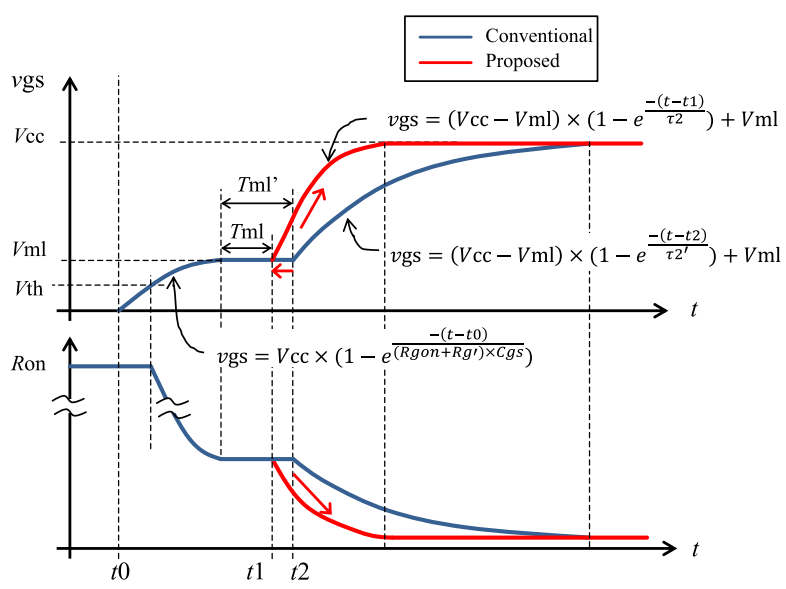

Fig. 9. Turn-on delay and loss reduction method illustration for the proposed gate driver

constant of Delay circuit is calculated with (1) where $R 1 \ll$ $R 2$. The delay time $t$ dbst is calculated with (2) where $V$ thbst is the Qbst gate threshold voltage. The delay time $t$ dbst must be longer than the total of turn on delay $t \mathrm{~d}($ on) and drain current rise time $\operatorname{tr}(i)$ as (3). The turn-on delay time $t \mathrm{~d}(\mathrm{on})$ can be obtained from (4). Finally $t$ dbst is determined according to (5) where $V$ th_cold is the maximum gate threshold voltage at the lowest operating temperature, as the MOSFET's $V$ th increases at lower temperatures.

$$
\begin{aligned}
& \tau \mathrm{bst}=R 1 \times(C \mathrm{bst}+C \mathrm{gbst}) \\
& t \mathrm{dbst}=\tau \mathrm{bst} \times \ln \left(\frac{V \mathrm{cc}}{V \mathrm{cc}-V \text { thbst }}\right) \ldots \\
& t \mathrm{dbst} \geq t \mathrm{~d}(\text { on })+t \mathrm{r}(i) \ldots \ldots \ldots \ldots \ldots \ldots \ldots \ldots \\
& t \mathrm{~d}(\text { on })=R \text { gon } \times C \operatorname{gs} \times \ln \left(\frac{V \mathrm{cc}}{V \mathrm{cc}-V \mathrm{th}}\right) \\
& t \text { dbst } \geq R \operatorname{gon} \times C \operatorname{gs} \times \ln \left(\frac{V \text { cc }}{V \text { cc }-V \text { th_cold }}\right)+t \mathrm{r}(i) \cdots
\end{aligned}
$$

Figure 9 explains how the proposed gate driver works for faster and lower loss turn-on switching. First, the proposed gate driver reduces the Miller period with the gate boost current $i$ gbst. The Miller period $T \mathrm{ml}$ for the proposed gate driver is calculated with (6), whereas the Miller period $T \mathrm{ml}$ ' for the conventional gate driver is calculated with (7). The proposed gate driver charges the input capacitance with a higher current than the conventional gate driver, being able to reduce the Miller period as (8).

$$
\begin{aligned}
& T \mathrm{ml}=(C \mathrm{gs}+C \mathrm{gd}) \times \Delta V \mathrm{ds} /(i \mathrm{gon}+i \mathrm{gbst}) \\
& T \mathrm{ml}^{\prime}=(C \mathrm{gs}+C \mathrm{gd}) \times \Delta V \mathrm{ds} / \text { igon } \ldots \ldots \ldots \ldots \ldots . \\
& T \mathrm{ml}<T \mathrm{ml}^{\prime}
\end{aligned}
$$

The proposed gate driver also reduces the gate charge time constant $\tau 2$ following the Miller plateau, with the gate boost current igbst. $\tau 2$ for the proposed gate driver is calculated with (9), where $R \mathrm{~g}$ ' is the internal gate resistance of the SiC-MOSFETs. The time constant for the conventional gate driver $\tau 2$ ' is calculated with (10). Thus, the proposed gate driver pushes up gate voltage faster compared to the conventional gate drivers. The higher gate voltage yields lower onstate resistance $R$ on; thus, the proposed gate driver lowers the SiC-MOSFET on-state resistance faster than the conventional gate drivers. Finally, the proposed gate driver reduces

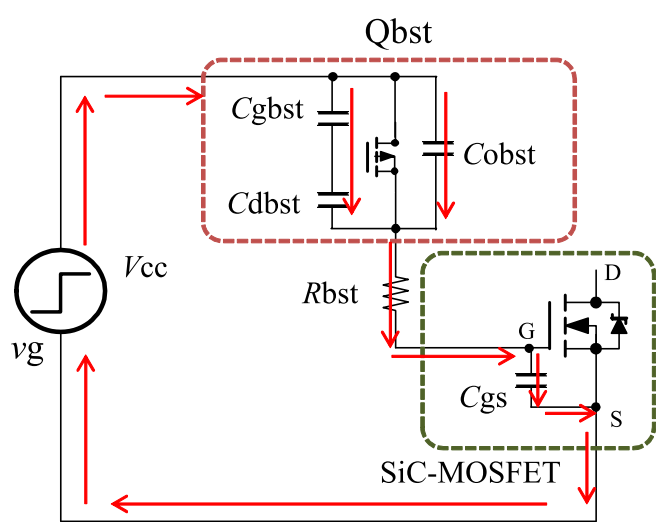

Fig. 10. Influence of the gate boost switch parasitic elements

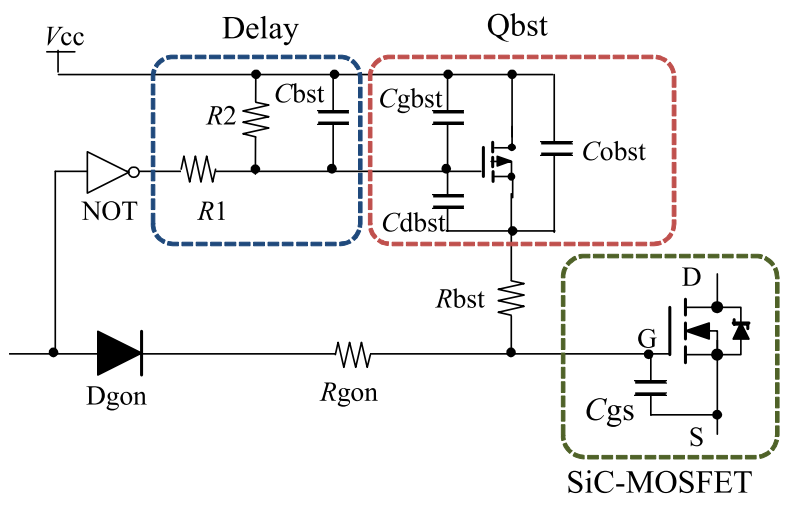

Fig. 11. Enhanced gate boost circuit schematic example

the turn-on loss. Certain commercialized SiC-MOSFETs tend to require relatively higher gate driving voltage than SiMOSFETs, owing to their relatively large channel resistance. The gate drive capability of the proposed gate driver matches the $\mathrm{SiC}-\mathrm{MOSFETs}$ requirements.

$$
\begin{aligned}
& \tau 2=\left(\frac{R \text { gon } \times R \mathrm{bst}}{R \text { gon }+R \mathrm{bst}}+R \mathrm{~g}^{\prime}\right) \times(C \mathrm{gs}+C \mathrm{gd}) \cdots \ldots . \\
& \tau 2^{\prime}=\left(\operatorname{Rgon}^{\prime}+R \mathrm{~g}^{\prime}\right) \times(C \mathrm{gs}+C \mathrm{gd}) \\
& \tau 2<\tau 2^{\prime} \text {. }
\end{aligned}
$$

Figure 10 shows the influence of the gate boost switch parasitic elements on the SiC-MOSFET gate charging process. When the gate driver's input voltage $v \mathrm{~g}$ rises to $V \mathrm{cc}$ level, the parasitic capacitance inrush charge current flows through $R \mathrm{bst}$. This gate charge current might create the risk of a too fast turn-on. Thus, to avoid this risk, $C$ obst, $C$ gbst, and $C$ dbst must be significantly smaller than $C$ gs. Consequently, Qbst must meet (12).

$$
V \text { th } \gg V \mathrm{cc} \times\left(\frac{C \text { obst }+\frac{C \text { gbst } \times C \text { dbst }}{C \text { gbst }+C \mathrm{dbst}}}{C \mathrm{gs}}\right) \ldots \ldots \ldots
$$

Figure 11 shows the schematic of an enhanced gate boost circuit that could prevent the inrush current as emphasized in Fig. 10. The drain of Qbst is connected to a stable voltage source $V \mathrm{cc}$; thus, the inrush charge current does not occur. This circuit works stably but it requires an additional inverting gate that introduces a time delay $t$ dnot. The boost delay time $t \mathrm{dbst}$ for this circuit is calculated in (13). 


$$
t \mathrm{dbst}=t \mathrm{~d}_{\text {not }}+\tau \mathrm{bst} \times \ln \left(\frac{V \mathrm{cc}}{V \mathrm{cc}-V \text { thbst }}\right) \cdots \cdots \cdots
$$

Next, the paper also describes how chose the speed-up capacitor $C$ sp and turn-off gate resistor Rgoff selection method.

Once the turn-off seauence starts, the speed-up capacitor $C$ sp discharges the SiC-MOSFET gate down to Vgsp according to (14). Vgsp must also be higher than SiC-MOSFET Miller voltage $V \mathrm{ml}$. Thus, the maximum limit of $C \mathrm{sp}$ is calculated in (15). Gate discharging turn-off time constant for the proposed gate driver should exhibit a similar value with that of the conventional gate driver as expressed in (16), where Rgoff' is the turn-off gate resistor for the conventional gate driver as shown in Fig. 2 and $C$ iss is the input capacitance of the SiC-MOSFET. Thus, the turn-off gate resistor value $R$ goff for the proposed gate driver is calculated in (17).

For example, if the design conditions are $V \mathrm{cc}=18 \mathrm{~V}, V \mathrm{ml}$ $=3 \mathrm{~V}, C$ sp must be chosen to satisfy $C \mathrm{sp}<5 C$ iss. If $C \mathrm{sp}=$ $C$ iss, neglecting the forward voltage drop across Dgoff, the $C$ sp discharge to half of the $V \mathrm{cc}$ voltage. The gate resistor of the proposed gate driver Rgoff should be set to about half of the gate resistor value for the conventional gate driver Rgoff'. Thus, the turn-off delay time can be reduced without a significant change in voltage surge or drain voltage transient $\mathrm{d} V / \mathrm{d} t$.

$$
\begin{aligned}
& V \text { gsp }=V \mathrm{cc} \times \frac{C \text { iss }}{C \text { iss }+C \text { sp }}>V \mathrm{ml} \cdots \\
& C \text { sp }<C \text { iss } \times\left(\frac{V \mathrm{cc}}{V \mathrm{ml}}-1\right) \ldots \ldots \ldots \\
& R \text { goff } \times(C \text { iss }+C \text { sp })=R \text { goff } \times C \text { iss } \\
& R \text { goff }=R \text { goff }^{\prime} \times \frac{C \text { iss }}{C \text { iss }+C \text { sp }} \cdots \cdots
\end{aligned}
$$

\section{Switching Characteristics Evaluation}

3.1 Experimental Setup for Evaluation Figure 12 shows double pulse test (DPT) setup for the switching characteristics evaluation. Figure 13 shows the definitions adopted in this paper for the switching characteristics. We define Eon 2 and ton 2 to evaluate the energy loss and delay subsequent to the drain current transient during the turn-on sequence.

Figure 14 shows the test setup photographs for noise evaluation in the DPt. We measured radio noise emissions from the $\mathrm{SiC}$-MOSFET power module with an RF probe and oscilloscope MDO4054B-3 (Tektronix). The following test conditions were used: dc input voltage $E=400 \mathrm{~V}$, drain current $I \mathrm{~d}$ is set up to $100 \mathrm{~A}, \mathrm{SiC}-\mathrm{MOSFETs}$ power module case temperature $T \mathrm{c}$ set to room temperature (about $23^{\circ} \mathrm{C}$ ) or $100^{\circ} \mathrm{C}$, inductive load is approximately $100 \mu \mathrm{H}$, gate driver voltage source $V \mathrm{cc}=18 \mathrm{~V}$. The SiC-MOSFETs under test in this research are full $\mathrm{SiC}$ power modules, BSM120D12P2C005 (ROHM, $1200 \mathrm{~V}, 120 \mathrm{~A}$ ). The cables between the gate drive board and the power module are approximately $50 \mathrm{~mm}$ long.

The evaluation results compare the switching characteristics for the proposed and the conventional gate driver. The driver circuit components are selected as follows: $R$ gon $=$ $4.3 \Omega, R$ goff $=3.3 \Omega, R \mathrm{bst}=0 \Omega$, and $C \mathrm{sp}=22 \mathrm{nF}$ for the proposed gate driver (as shown in Fig. 1.) and Rgon' $=3.0 \Omega$, $R$ goff' $=5.1 \Omega$ for the conventional gate driver (shown in Fig. 2). Rbst is set in this case to $0 \Omega$ make the gate boost work well even with the long cables between the gate driver

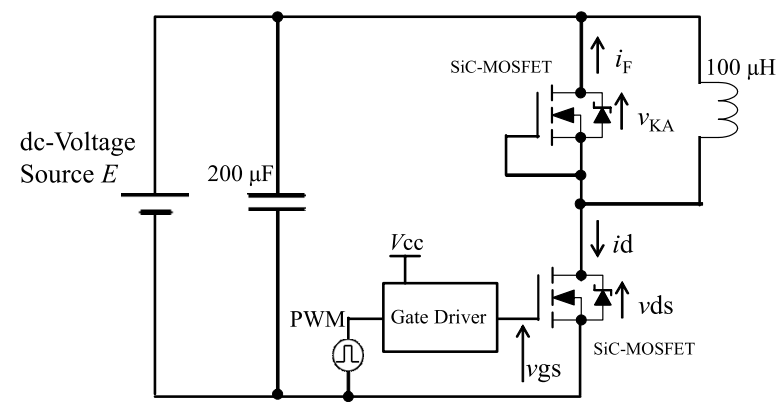

Fig. 12. Setup for double-pulse test
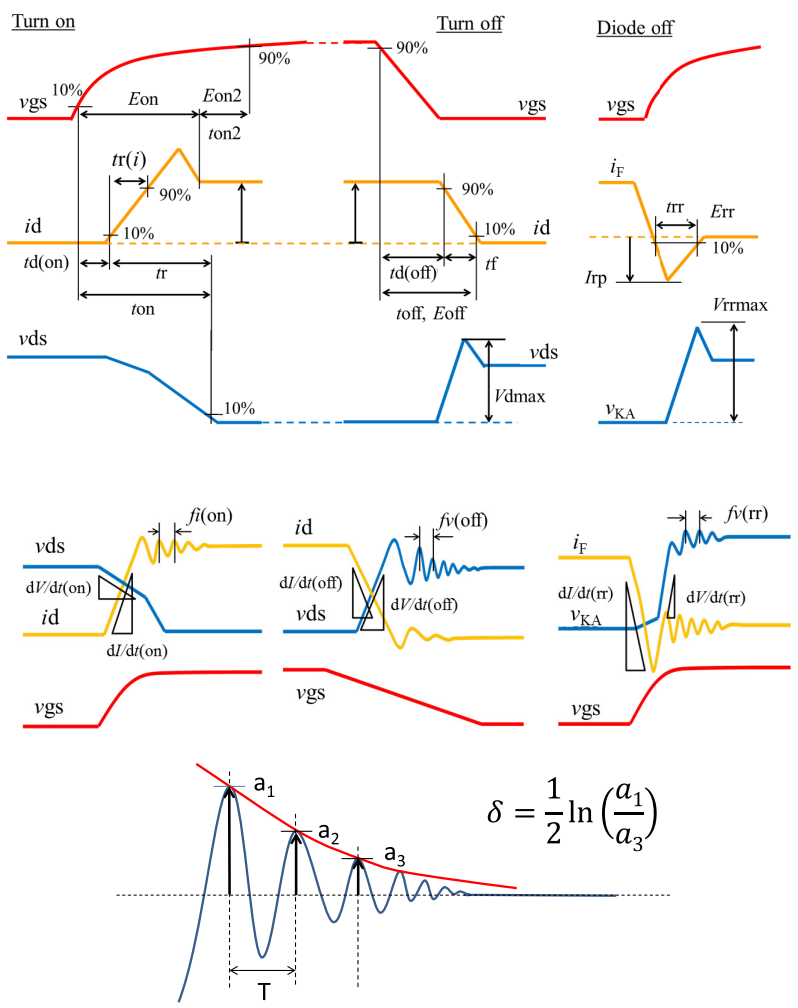

Fig. 13. Definitions of switching characteristics

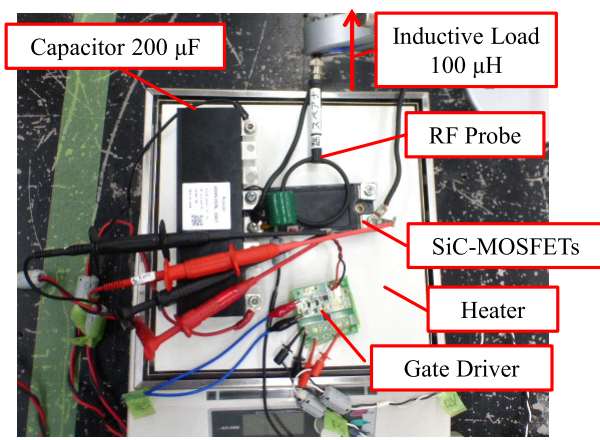

(a) Top view

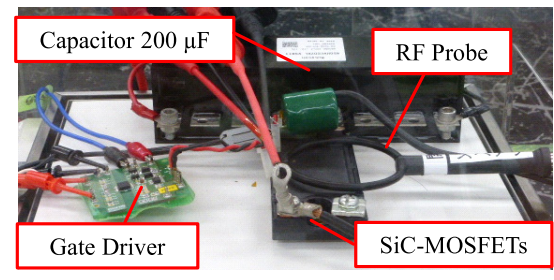

(b) Side view

Fig. 14. Test set up for noise evaluation in DPT 


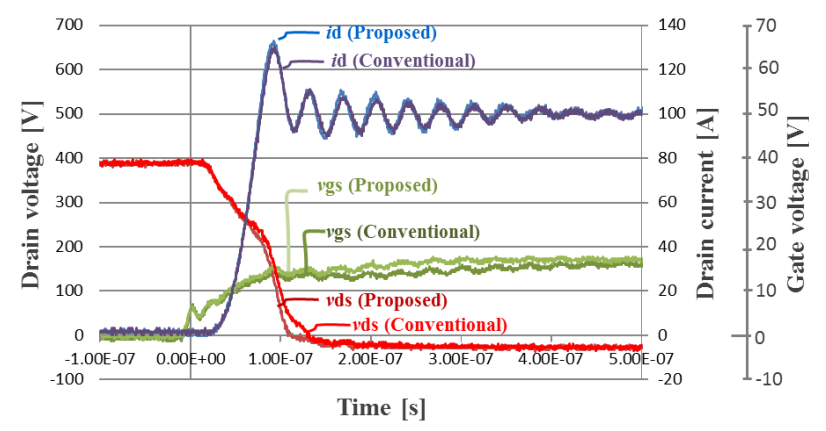

Eon: $0.95 \mathrm{~mJ}$ (Proposed), $1.05 \mathrm{~mJ}$ (Conventional) Eon2: $0.206 \mathrm{~mJ}$ (Proposed), $0.613 \mathrm{~mJ}$ (Conventional) fi(on): 27.4 MHz (Proposed), 26.7 MHz (Conventional) $\delta: 0.604$ (Proposed), 0.998 (Conventional)

Fig. 15. Turn-on wave forms, $E=400 \mathrm{~V}, I \mathrm{~d}=100 \mathrm{~A}, T \mathrm{c}$ $=100^{\circ} \mathrm{C}, V \mathrm{cc}=18 \mathrm{~V}$, for the proposed gate driver: $R$ gon $=4.3 \Omega, R$ goff $=3.3 \Omega, R \mathrm{bst}=0 \Omega$, and $C \mathrm{sp}=22 \mathrm{nF}$, for the conventional gate driver: Rgon' $=3 \Omega, R$ goff' $=5.1 \Omega$

and the power module. These component values were determined using the design methods introduced in the previous section, selected to achieve roughly the same switching transients $\mathrm{d} V / \mathrm{d} t$ and $\mathrm{d} I / \mathrm{d} t$ for both drivers under test.

3.2 Turn-on Characteristics Figure 15 shows the turn-on waveforms at $400 \mathrm{~V}, 100 \mathrm{~A}$, and $T \mathrm{c}=100^{\circ} \mathrm{C}$. The turn-on loss $E$ on $=0.95 \mathrm{~mJ}, E$ on $2=0.21 \mathrm{~mJ}$ for the proposed gate driver, whereas $E$ on $=1.05 \mathrm{~mJ}, E$ on $2=0.61 \mathrm{~mJ}$ for the conventional driver. The waveforms confirmed that the proposed gate driver pushes up the gate voltage $v$ gs faster than the conventional driver, reducing switching loss and delay time. Moreover, the drain peak current and ringing are essentially unchanged, providing that the switching noise does not increase.

Figure 16 shows the turn-on losses Eon, Eon2, and turn-on time ton 2 against drain current at $E=400 \mathrm{~V}$. The proposed gate driver reduces the turn-on loss approximately $30 \%$ maximum from the conventional driver at $T \mathrm{c}=100^{\circ} \mathrm{C}$, also reducing the turn-on delay subsequent to the drain current transient $t$ on2. Eon decreases as temperature increases, because $V$ th decreases as temperature increases; therefore, the earlier turn-on transition period becomes shorter, resulting in lower Eon. In contrast, Eon2 increases as temperature increases, because the gate resistances (which include power module internal gate resistance) become larger as temperature increases; therefore, the gate drive time constant increases, resulting in higher Eon2.

Figure 17 shows the current transient rate $\mathrm{d} I / \mathrm{d} t$ (on) and current ringing frequency $f($ on) during the turn-on sequence.

The proposed gate driver exhibits an essentially unchanged $\mathrm{d} I / \mathrm{d} t$ (on) compared to the conventional gate driver in spite of its lower switching loss capability. The drain current ringing frequencies are similar for both the proposed gate driver and the conventional driver. However the drain current ringing damping factor of the proposed gate driver is slightly smaller than that of the conventional gate driver as shown in Fig. 15. The proposed gate driver can reduce the on-state resistance faster than the conventional driver, and then makes the damping resistance smaller.

The experimental results in this section confirmed that the

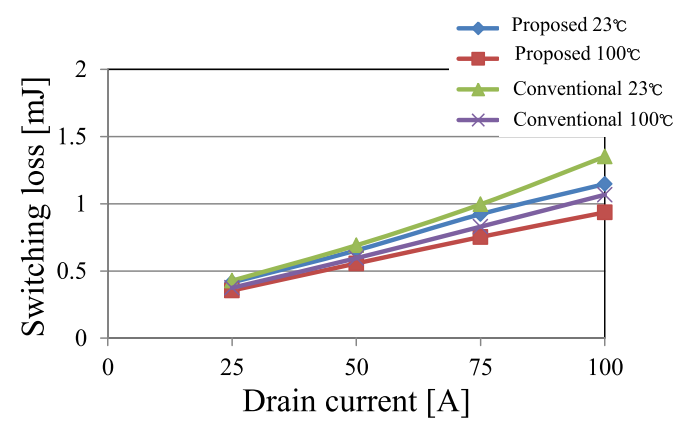

(a) Eon

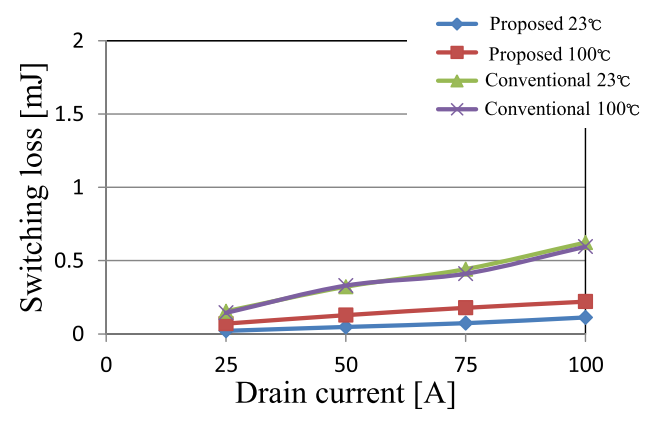

(b) Eon2

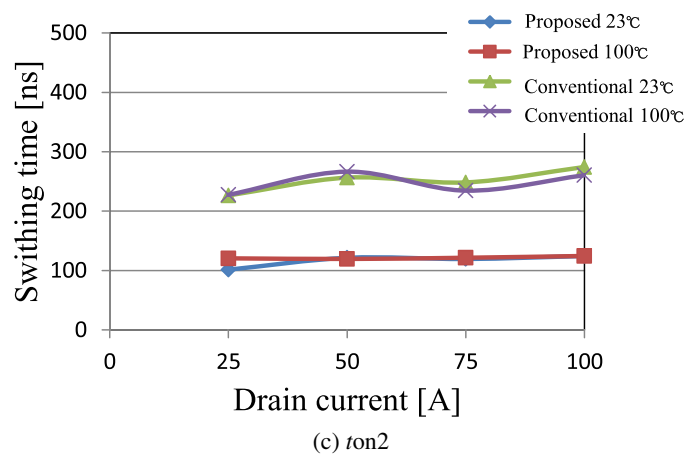

Fig. 16. Turn-on characteristics, (a) Eon, (b) Eon2, (c) $t$ on $2, E=400 \mathrm{~V}, V \mathrm{cc}=18 \mathrm{~V}$, for the proposed gate driver: $R$ gon $=4.3 \Omega, R$ goff $=3.3 \Omega, R$ bst $=0 \Omega$, and $C \mathrm{sp}=$ $22 \mathrm{nF}$, for the conventional gate driver: Rgon' $=3 \Omega$, Rgoff' $=5.1 \Omega$

proposed gate driver simultaneously achieves fast low-loss switching and low-noise switching, and breaks the trade-off of switching performances.

3.3 Turn-off Characteristics Figure 18 shows the turn-off waveforms at $400 \mathrm{~V}, 100 \mathrm{~A}$, and $T \mathrm{c}=100^{\circ} \mathrm{C}$. Figure 19 shows the turn-off delay time $t \mathrm{~d}$ (off) and turn-off loss Eoff.

As shown in Fig. 18, the proposed gate driver quickly discharges the gate capacitance and reduces the turn-off delay time with the speed-up capacitor. The turn-off loss Eoff is approximately $2.4 \mathrm{~mJ}$, and the turn-off delay time $t \mathrm{~d}$ (off) is $190 \mathrm{~ns}$ for the proposed gate driver. The turn-off loss Eoff is approximately $2.4 \mathrm{~mJ}$, the turn-off delay time $t \mathrm{~d}$ (off) is $284 \mathrm{~ns}$ for the conventional gate driver. The proposed gate driver reduces the turn-off delay time with approximately $30 \%$.

As shown in Fig. 19(a), the proposed gate driver reduces the turn-off delay time $t \mathrm{~d}$ (off) over a wide range of drain currents and temperatures. $t \mathrm{~d}(\mathrm{off})$ increases as temperature increases because the gate resistances increase with temperature; therefore, the gate drive time constants become larger, 


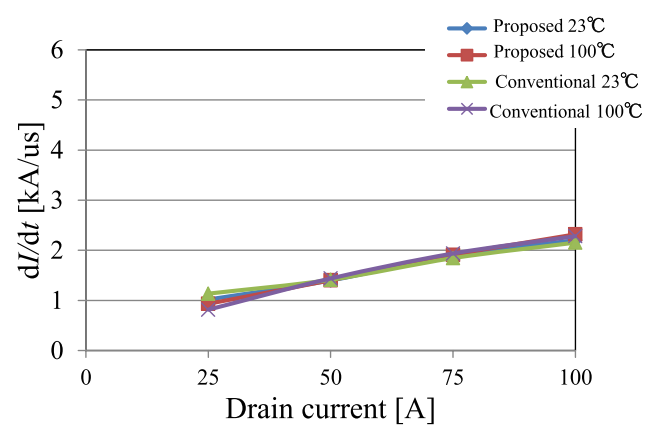

(a) $\mathrm{d} I / \mathrm{d} t$ (on)

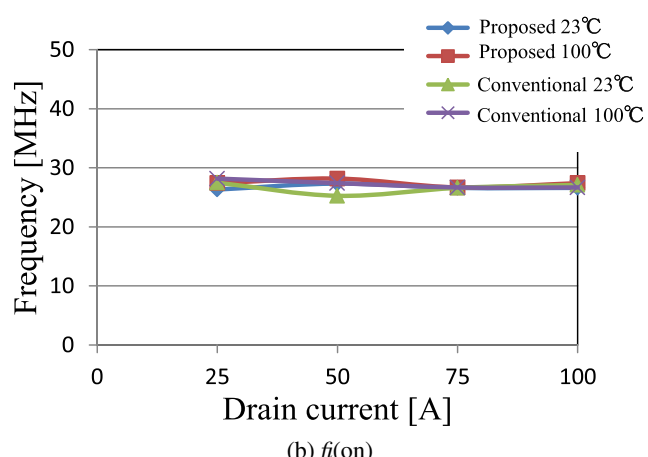

Fig. 17. Turn-on characteristics related to switching noise, (a) $\mathrm{d} I / \mathrm{d} t$ (on), (b) $f($ on), $E=400 \mathrm{~V}, V \mathrm{cc}=18 \mathrm{~V}$, for the proposed gate driver: $R$ gon $=4.3 \Omega, R$ goff $=3.3 \Omega$, $R \mathrm{bst}=0 \Omega$, and $C \mathrm{sp}=22 \mathrm{nF}$, for the conventional gate driver: $R$ gon' $=3 \Omega$, Roff' $=5.1 \Omega$

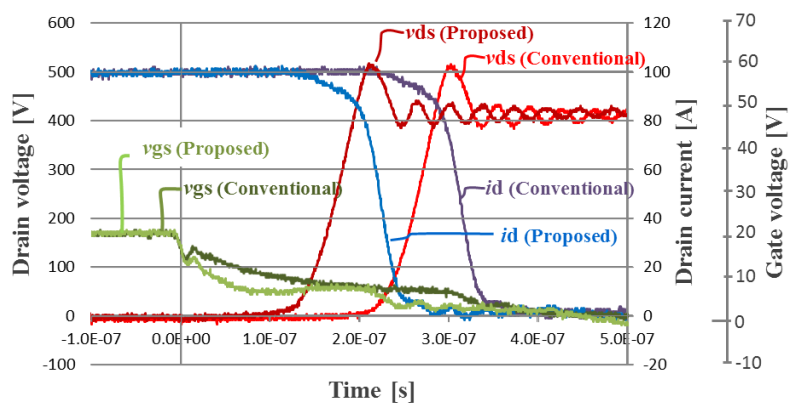

td(off):190 ns (Proposed), 284 ns (Conventional)

Eoff: $2.397 \mathrm{~mJ}$ (Proposed), $2.403 \mathrm{~mJ}$ (Conventional)

fv(off): 27.4 MHz (Proposed), 26.7 MHz (Conventional) $\delta: 0.655$ (Proposed), 0.703 (Conventional)

Fig. 18. Turn-off wave forms, $E=400 \mathrm{~V}, I \mathrm{~d}=100 \mathrm{~A}, T \mathrm{c}$ $=100^{\circ} \mathrm{C}, V \mathrm{cc}=18 \mathrm{~V}$, for the proposed gate driver: Rgon $=4.3 \Omega, R$ goff $=3.3 \Omega, R \mathrm{bst}=0 \Omega$, and $C \mathrm{sp}=22 \mathrm{nF}$, for the conventional gate driver: $R$ gon' $=3 \Omega$, goff' $=5.1 \Omega$

resulting in a longer $t \mathrm{~d}(\mathrm{off})$. The proposed gate driver is designed to exhibit similar driving characteristics during the drain voltage transient; thus, the turn-off loss Eoff is essentially identical for both drivers.

Figure 20 shows the voltage transient rate $\mathrm{d} V / \mathrm{d} t($ off $)$, maximum voltage overshoot $V \mathrm{dmax}$, and voltage ringing frequency $f v$ (off) during the turn-off sequence. The proposed gate driver exhibits almost same voltage overshoot $V$ dmax, and voltage ringing characteristics with the conventional gate driver in spite of its faster switching capability. However, as the drain voltage transient rate $\mathrm{d} V / \mathrm{d} t$ (off) slightly increased for the proposed gate driver, we experimentally evaluated the

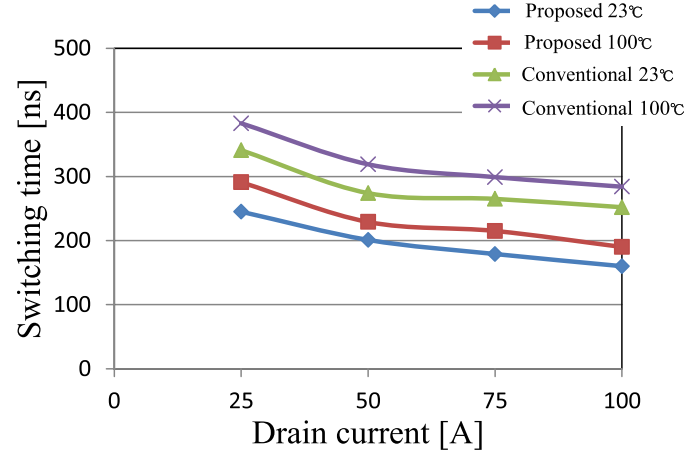

(a) $t \mathrm{~d}($ off)

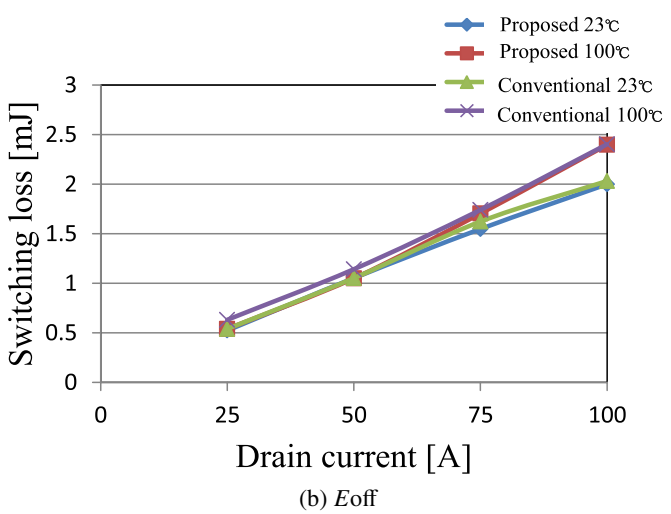

Fig. 19. Turn-off characteristics, (a) $t$ d(off), (b) Eoff, $E$ $=400 \mathrm{~V}, V \mathrm{cc}=18 \mathrm{~V}$, for the proposed gate driver: $R$ gon $=4.3 \Omega$, Roff $=3.3 \Omega, R \mathrm{bst}=0 \Omega$, and $C \mathrm{sp}=22 \mathrm{nF}$, for the conventional gate driver: $R$ gon' $=3 \Omega$, goff' $=5.1 \Omega$

impact of the $\mathrm{d} V / \mathrm{d} t$ on EMI, as described in the following sections.

The experimental results confirmed that the proposed gate driver enhances the switching performances, and simultaneously achieving fast switching and low-noise switching.

3.4 Diode Switching Characteristics Figure 21 shows the diode turn-off waveforms at $400 \mathrm{~V}, 100 \mathrm{~A}$, and $T \mathrm{c}$ $=100^{\circ} \mathrm{C}$. The diode turn-off loss $E \mathrm{rr}=0.24 \mathrm{~mJ}$ for the proposed gate driver, whereas $E \mathrm{rr}=0.26 \mathrm{~mJ}$ for the conventional driver. Figure 22 shows Err against drain current at $400 \mathrm{~V}$.

Figure 23 shows the voltage transient rate $\mathrm{d} V / \mathrm{d} t(\mathrm{rr})$ and voltage ringing frequency $f v(\mathrm{rr})$ during the diode turn-off sequence.

No significant differences were found for the diode turnoff characteristics between the proposed and the conventional gate driver. As a faster turn-on capability is usually associated with hard diode switching, it would be expected that the proposed gate driver, which reduces the turn-on loss and delay time, would exhibit worse diode turn-off performance. However, as the experimental results confirmed, the proposed gate driver prevents the deterioration of the diode switching characteristics.

3.5 RF Noise Emissions and Total Switching Loss

Figure 24 shows RF switching noise frequency spectrum of RF switching noise emissions up to $100 \mathrm{MHz}$, measured in the test setup presented in Figs. 12 and 14. The test conditions are as follows: $E=400 \mathrm{~V}, I \mathrm{~d}=100 \mathrm{~A}, T \mathrm{c}=$ approximately $23^{\circ} \mathrm{C}, V \mathrm{cc}=18 \mathrm{~V}$. Figure 25 shows the total switching loss per switching cycle.

The proposed and the conventional gate drivers have quite 

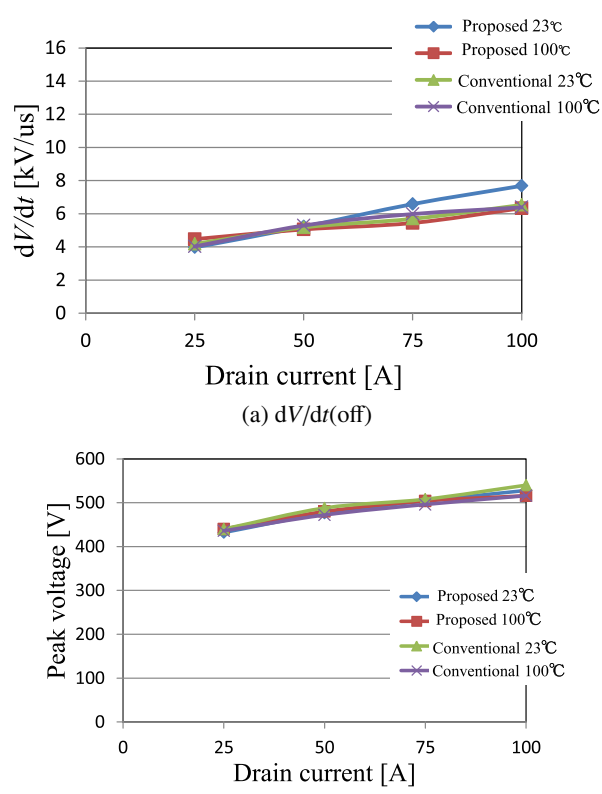

(b) $V$ dmax

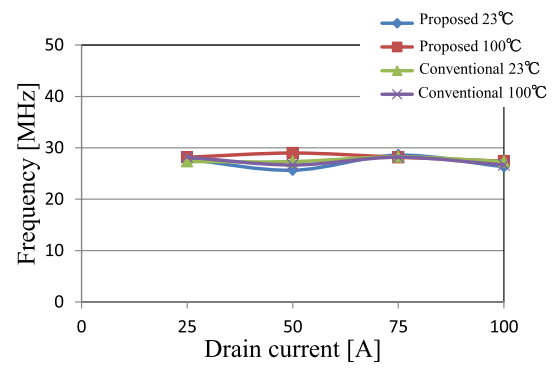

(c) $f v$ (off)

Fig. 20. Turn-off characteristics related to switching noise, (a) $\mathrm{d} V / \mathrm{d} t$ (off), (b) $V \mathrm{dmax}$, (c) $f v$ (off), $E=400 \mathrm{~V}$, $V \mathrm{cc}=18 \mathrm{~V}$, for the proposed gate driver: $\operatorname{Rgon}=4.3 \Omega$, $R$ goff $=3.3 \Omega, R \mathrm{bst}=0 \Omega$, and $C \mathrm{sp}=22 \mathrm{nF}$, for the conventional gate driver: $R$ gon' $=3 \Omega, R$ goff' $=5.1 \Omega$

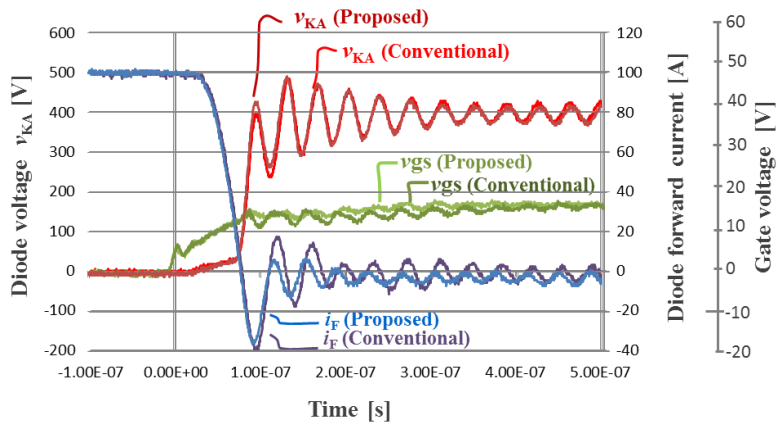

Err: $0.244 \mathrm{~mJ}$ (Proposed), $0.258 \mathrm{~mJ}$ (Conventional) $f v(\mathrm{rr}):$ 28.2 MHz (Proposed), 28.2 MHz (Conventional) $\delta: 0.243$ (Proposed), 0.227 (Conventional)

Fig. 21. Diode turn-off wave forms, $E=400 \mathrm{~V}, I \mathrm{~d}=$ $100 \mathrm{~A}, T \mathrm{c}=100^{\circ} \mathrm{C}, V \mathrm{cc}=18 \mathrm{~V}, R$ gon $=4.3 \Omega, R$ goff $=$ $3.3 \Omega, R$ bst $=0 \Omega$, and $C$ sp $=22 \mathrm{nF}$, Rgon' $=3 \Omega, R$ goff' $=5.1 \Omega$

similar frequency spectra. No critical disadvantage was noticed for the proposed gate driver in terms of noise emissions. The proposed gate driver exhibits lower noise emissions than the conventional gate driver for certain frequencies marked with red circles in Fig. 24.

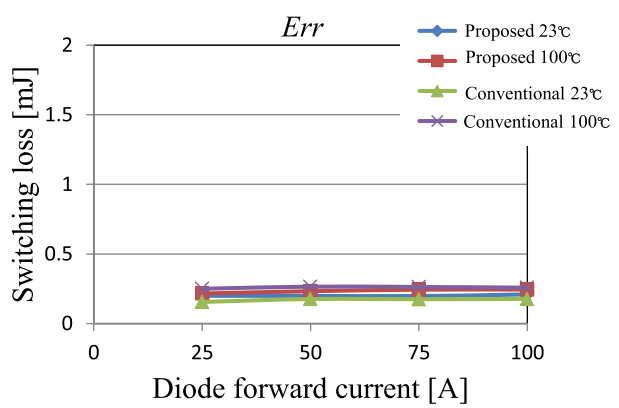

Fig. 22. Diode turn-off loss $E \mathrm{rr}, E=400 \mathrm{~V}, V \mathrm{cc}=18 \mathrm{~V}$, $R$ gon $=4.3 \Omega, R$ goff $=3.3 \Omega, R$ bst $=0 \Omega$, and $C$ sp $=$ $22 \mathrm{nF}$, Rgon' $=3 \Omega$, Rgoff' $=5.1 \Omega$

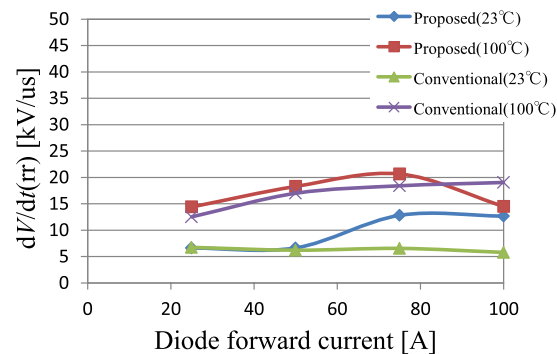

(a) $\mathrm{d} V / \mathrm{d} t(\operatorname{tr})$

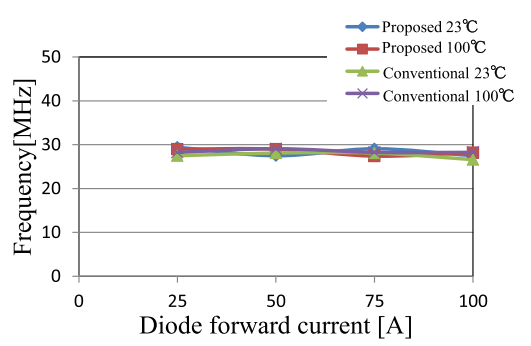

(b) $f v(\mathrm{rr})$

Fig. 23. Diode turn-off characteristics related to switching noise, (a) $\mathrm{d} V / \mathrm{d} t$ (rr), (b) $f v$ (off), $E=400 \mathrm{~V}, V \mathrm{cc}=18 \mathrm{~V}$, $R$ gon $=4.3 \Omega, R$ goff $=3.3 \Omega, R$ bst $=0 \Omega$, and $C$ sp $=$ $22 \mathrm{nF}, R$ gon' $=3 \Omega, R$ goff' $=5.1 \Omega$

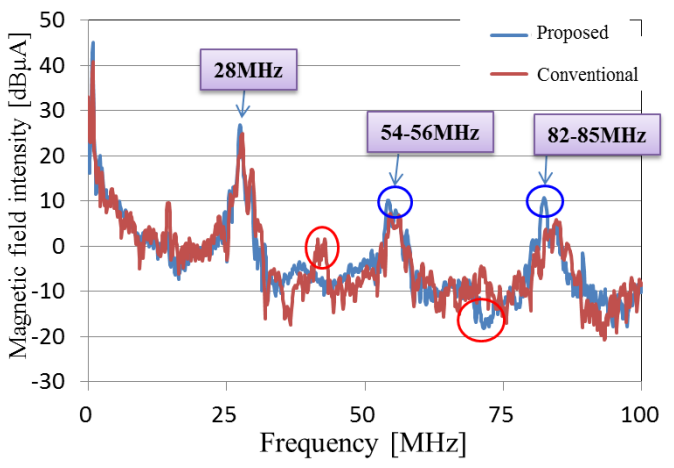

Fig. 24. RF noise emission at switching, $E=400 \mathrm{~V}, I \mathrm{~d}$ $=100 \mathrm{~A}, T \mathrm{c}=23^{\circ} \mathrm{C}, V \mathrm{cc}=18 \mathrm{~V}, R$ gon $=4.3 \Omega, R$ goff $=$ $3.3 \Omega, R$ bst $=0 \Omega$, and $C \mathrm{sp}=22 \mathrm{nF}, R$ gon' $=3 \Omega$, Rgoff' $=5.1 \Omega$

In contrast, the proposed gate driver has slightly higher noise emissions for certain frequencies marked with blue circles in Fig. 24; these frequencies are switching ringing frequency harmonics. The smaller damping factors of the proposed gate driver influenced the results. The higher $\mathrm{d} V / \mathrm{d} t$ of the proposed gate driver, however, did not critically influence the noise emissions in the experiments. The spectrum 


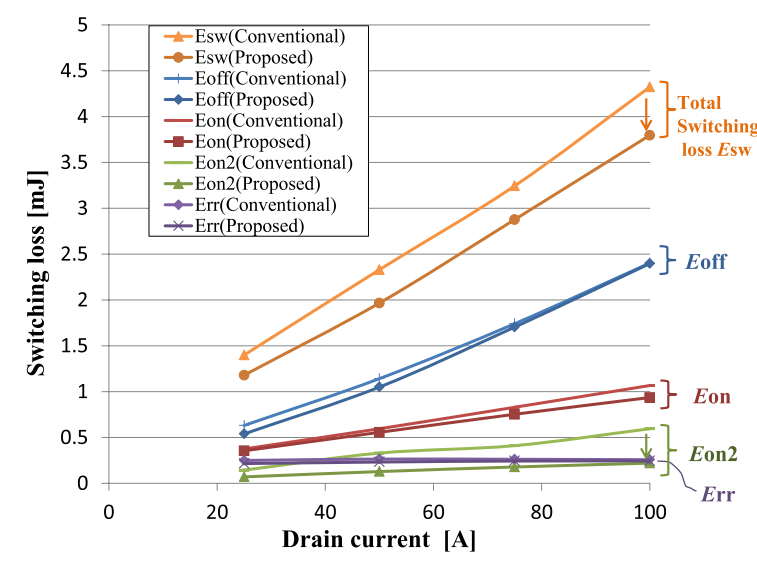

Fig. 25. Total switching loss, $E=400 \mathrm{~V}, T \mathrm{c}=100^{\circ} \mathrm{C}$, $V \mathrm{cc}=18 \mathrm{~V}, R$ gon $=4.3 \Omega, R$ goff $=3.3 \Omega, R \mathrm{bst}=0 \Omega$, and $C \mathrm{sp}=22 \mathrm{nF}, R$ gon' $=3 \Omega$, gooff' $=5.1 \Omega$

associated with the measured $\mathrm{d} V / \mathrm{d} t$ should be less than $15 \mathrm{MHz}$.

As shown in Fig. 25, the proposed gate driver reduces the total switching loss with about $12 \%$ compared to the conventional gate driver loss. The experimental results confirmed that the proposed gate driver exhibits low loss switching capability without increasing radiated switching noise emission.

\section{Evaluation of SiC-MOSFETs Inverter}

This section shows the evaluation results of a SiCMOSFETs inverter using the proposed gate driver.

Figure 26 and Fig. 27 show the test setup for evaluating the inverter loss and noise. We evaluated the inverter loss using an inductive load, which could easily change the inverter output current up to the maximum rated current of 60 Arms. The load inductance $=$ approximately $100 \mu \mathrm{H}$ and the load resistance $=$ approximately $0.97 \Omega$ for each phase; therefore, the maximum inverter output power was about $10 \mathrm{~kW}$. The inverter output frequency $=$ approximately $666 \mathrm{~Hz}$. We also evaluated radiated noise from inverter, and also measured the common mode current during the motor drive operation, as shown in Figs. 26 and 27. The motor speed $=20,000 \mathrm{rpm}$, and motor pole number $=4$, therefore, the inverter output frequency = approximately $666 \mathrm{~Hz}$.

During the motor operation at $20,000 \mathrm{rpm}$, the inverter output voltage was approximately $148 \mathrm{Vrms}$, the inverter output current was approximately $1.65 \mathrm{Arms}$, and the inverter output power was approximately $330 \mathrm{~W}$, the output power and current were smaller than that during the test with inductive load since with no motor load. Inverter operating conditions are as follows: the dc voltage $V \mathrm{dc}=400 \mathrm{~V}$, the switching frequency $f \mathrm{sw}=20 \mathrm{kHz}$, and the dead time $t \mathrm{~d}=3 \mu \mathrm{s}$.

Figure 28 shows the experimental results of the inverter loss evaluation with the proposed gate driver and the conventional driver. The measured inverter loss includes all inverter power loss, excluding the control board loss. Figure 29 shows the radiated noise emission comparison between the $\mathrm{SiC}$-MOSFETs inverters with the proposed and the conventional gate driver. Figure 30 shows the comparison of the measured common mode current.

As shown in Fig. 28, the proposed gate driver reduces the

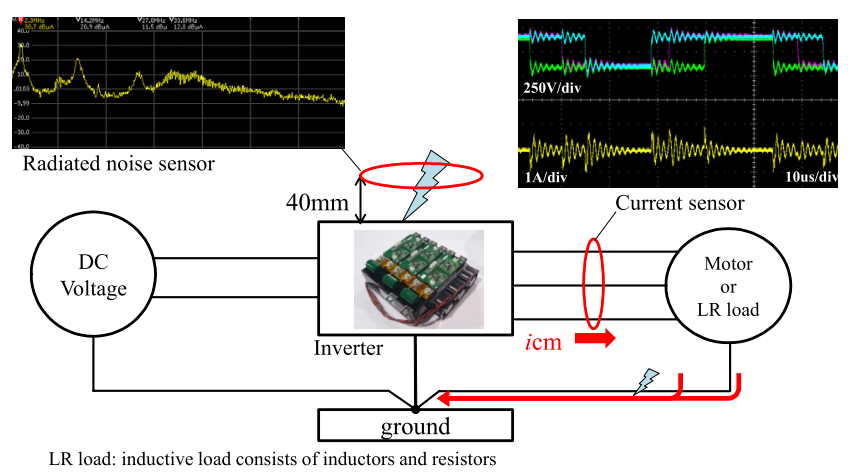

Fig. 26. SiC inverter noise test configuration

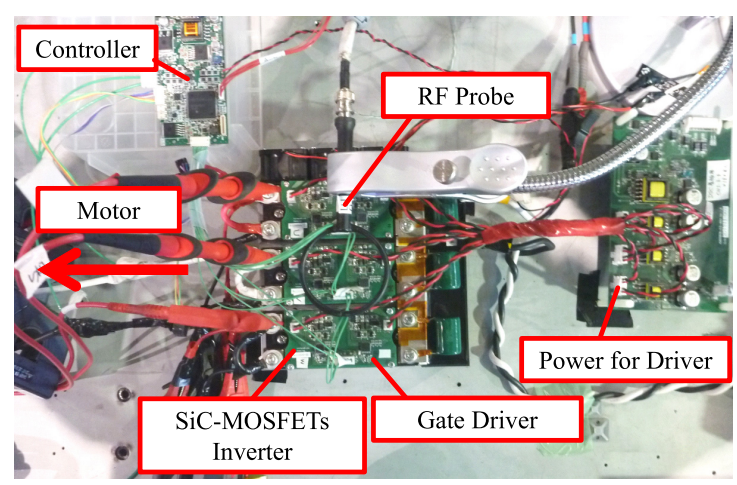

Fig. 27. Photograph of the SiC-MOSFETs inverter test configuration

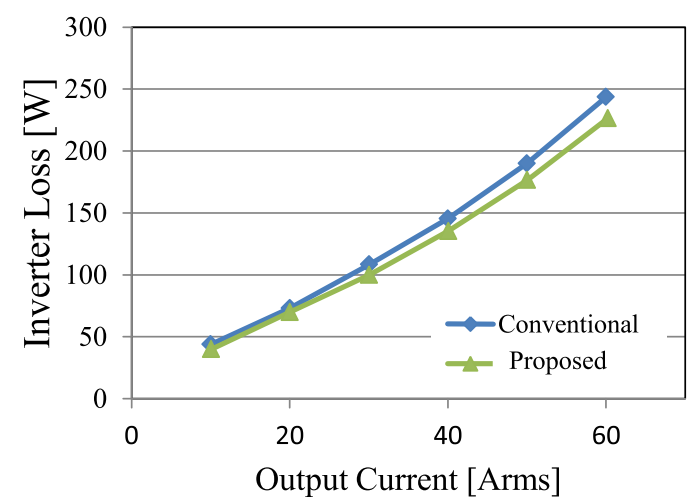

Fig. 28. Comparison of inverter loss, $V \mathrm{dc}=400 \mathrm{~V}, V \mathrm{cc}$ $=18 \mathrm{~V}, f \mathrm{sw}=20 \mathrm{kHz}, t \mathrm{~d}=3 \mu \mathrm{s}, R \mathrm{gon}=4.3 \Omega, R$ goff $=$ $3.3 \Omega, R \mathrm{bst}=0 \Omega$, and $C \mathrm{sp}=22 \mathrm{nF}, R$ gon' $=3 \Omega$, Rgoff' $=5.1 \Omega$

inverter loss with about $7 \%$ at the maximum output current, this result confirming the low loss performance of the proposed gate driver.

The experimental results of radiated noise emission as shown in Fig. 29 confirmed that the proposed gate driver does not produce any negative impact on the radiated noise emissions.

The $28 \mathrm{MHz}$ spectral component was determined to be generated by the switching ringing frequency, whereas the 14.2 $\mathrm{MHz}$ component was generated by the diode switching transient. The higher voltage transient rates during turn-off did not critically impact the noise emissions in the inverter motor drive operation.

The common mode current value shown in Fig. 30 confirmed that the inverter driven with the proposed gate driver 


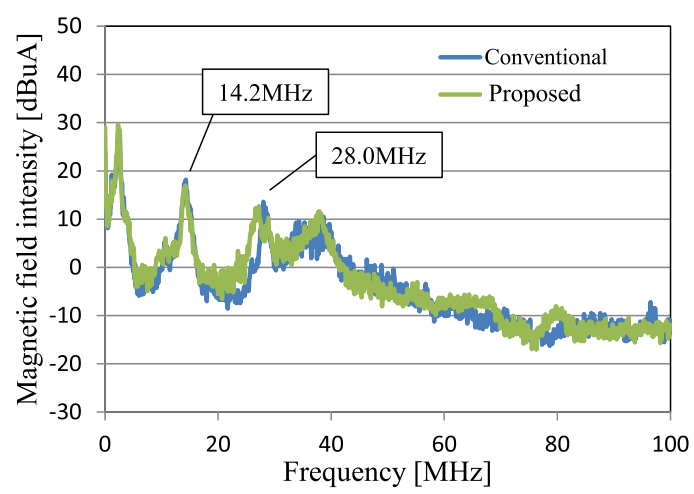

Fig. 29. Comparison of radiated noise emissions of the two inverters, $V \mathrm{dc}=400 \mathrm{~V}, V \mathrm{cc}=18 \mathrm{~V}, f \mathrm{sw}=20 \mathrm{kHz}, t \mathrm{~d}$ $=3 \mu \mathrm{s}, R$ gon $=4.3 \Omega, R$ goff $=3.3 \Omega, R$ bst $=0 \Omega$, and $C \mathrm{sp}$ $=22 \mathrm{nF}$, Rgon' $=3 \Omega$, Roff' $=5.1 \Omega$

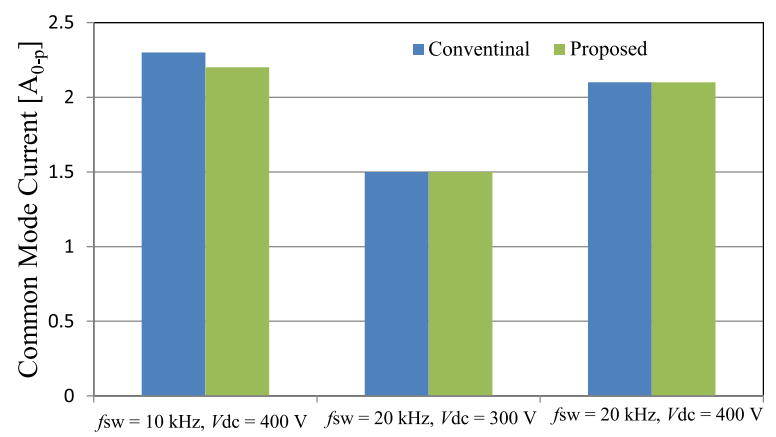

Fig. 30. Comparison of inverters' common mode currents, $V \mathrm{cc}=18 \mathrm{~V}, t \mathrm{~d}=3 \mu \mathrm{s}, R$ gon $=4.3 \Omega, R$ goff $=3.3 \Omega$, $R$ bst $=0 \Omega$, and $C$ sp $=22 \mathrm{nF}, R$ gon' $=3 \Omega, R$ goff' $=5.1 \Omega$

does not exhibit any higher common mode current than the inverter driven with the conventional gate driver. This result indicates that the conductive noise emissions are also not getting worse when using the proposed gate driver. The higher voltage transient rates during turn-off did not produce a critical impact on the common mode current in the inverter motor drive operation.

The experimental results shown in this section confirmed that the proposed gate driver reduces the inverter loss without increasing the inverter noise emissions.

\section{Conclusion}

We proposed the gate driver which is optimized for SiCMOSFETs. We confirmed through experimental results that the proposed gate driver makes it possible to solve the tradeoff of switching performances with experimental results. We comprehensively evaluated switching noise with $\mathrm{d} V / \mathrm{d} t$, ringing frequency, damping factor, and radiated noise emission, in addition to losses. The proposed gate driver reduces switching losses and switching delay time without increasing switching noise.

We also evaluated the proposed gate driver with a SiCMOSFETs inverter. Experimental results confirmed that the proposed gate driver reduces the inverter loss with about $7 \%$ without increasing the noise.

The low-loss switching performance achieved by the proposed gate driver could reduce the size and weight of cooling system or passive filter components. Our future work is to achieve higher power density converters.

\section{References}

(1) D. Peftitsis and J. Rabkowski: "Gate and Base Drivers for Silicon Carbide Power Transistors: An Overview", IEEE Trans. on Power Electronics, Vol.31, No.10, pp.7194-7212 (2016)

( 2 ) K. Yamaguchi, K. Katsura, and T. Yamada: "Comprehensive Evaluation and Design of SiC-Based High Power Density Inverter, $70 \mathrm{~kW} / \mathrm{liter}, 50 \mathrm{~kW} / \mathrm{kg}$ ", in Proc. IPEMC2016- ECCE Asia, Hefei, China (2016)

( 3 ) K. Yamaguchi: "Design and Evaluation of SiC-Based High Power Density Inverter, 70 kW/liter, 50 kW/kg”, in Proc. APEC2016, Long Beach, US (2016)

( 4 ) K. Takao, S. Harada, T. Shinohe, and H. Ohashi: "Performance Evaluation of All SiC Power Converters for Realizing High Power Density of $50 \mathrm{~W} / \mathrm{cm}^{3}$ ", in Proc. IPEC2010, pp.2128-2134, Japan (2010)

( 5 ) N. Oswald, P. Anthony, N. Mcneill, and B.H. Stark: "An Experimental Investigation of the Tradeoff between Switching Losses and EMI Generation With Hard-Switched All-Si, Si-SiC, and All-SiC Device Combinations", IEEE Trans. on Power Electronics, Vol.29, No.5, pp.2393-2407 (2014)

( 6 ) S. Yin, K.J. Tseng, P. Tu, R. Simanjorang, and A.K. Gupta: "Design Considerations and Comparison of High-speed Gate Drivers for Si IGBT and SiC MOSFET Modules", in Proc. IEEE 2016 Energy Conversion Congress \& Expo (ECCE2016), Milwaukee (2016)

( 7 ) S. Jahdi, O. Alatise, P. Alexakis, L. Ran, and P. Mawby: "The Impact of Temperature and Switching Rate on the Dynamic Characteristics of Silicon Carbide Schottky Barrier Diodes and MOSFETs", IEEE Trans. on Industrial Electronics, Vol.62, No.1, pp.163-171 (2015)

( 8 ) H. Chen and D. Divan: "High Speed Switching Issues of High Power Rated Silicon-Carbide Devices and the Mitigation Methods", in Proc. IEEE 2015 Energy Conversion Congress \& Expo (ECCE2015), Motreal (2015)

( 9 ) K. Vechalapu, S. Bhattacharya, E.V. Brunt, S.H. Ryu, D. Grider, and J.W. Palmour: "Comparative Evaluation of $15 \mathrm{kV} \mathrm{SiC} \mathrm{MOSFET} \mathrm{and} 15 \mathrm{kV} \mathrm{SiC}$ IGBT for Medium Voltage Converter under Same dv/dt Conditions", in Proc. IEEE 2015 Energy Conversion Congress \& Expo (ECCE2015), Montreal (2015)

(10) K. Yamaguchi and K. Katsura: "Research on Optimization Design of High Efficient Low Noise SiC-MOSFETs Inverters", in Proc. 9th International Conference on Power Electronics (ICPE2015 ECCE-Asia), pp.1442-1448, Seoul (2015)

(11) N. Idir, R. Bausiere, and J.J. Fauchaud: "Active Gate Voltage Control of Turn-on di/dt and Turn-off dv/dt in Insulated Gate Transistors", IEEE Trans. on Power Electronics, Vol.21, No.4, pp.849-855 (2006)

(12) P.J. Grbovic: "An IGBT Gate Driver for Feed-Forward Control of Turn-on Losses and Reverse Recovery Current", IEEE Trans. on Power Electronics, Vol.23, No.2, pp.643-652 (2008)

(13) X. Yang, Y. Yuan, Z. Long, J. Goncalves, and P.R. Palmer: "Robust Stability Analysis of Active Voltage Control for High Power IGBT Switching by Kharitonov's Theorem", IEEE Trans. on Power Electronics, Vol.31, No.3, pp.2584-2594 (2016)

(14) X. Yang, Y. Yuan, X. Zhang, and P.R. Palmer: "Shaping High-Power IGBT Switching Transitions by Active Voltage Control for Reduced EMI Generation", IEEE Trans. on Industry Applications, Vol.51, No.2, pp.1669-1677 (2015)

(15) K. Ishikawa, K. Ogawa, S. Yukutake, N. Kameshiro, and Y. Kono: "Traction Inverter that Applies Compact $3.3 \mathrm{kV} / 1200 \mathrm{~A}$ SiC Hybrid Module", The 2014 International Power Electronics Conference, pp.2140-2144 (2014)

(16) D. Aggeler, F. Canales, J. Biela, and J.W. Kolar: "Dv/Dt-Control Methods for the SiC JFET/Si MOSFET Cascode", IEEE Trans. on Power Electronics, Vol.28, No.8, pp.4074-4082 (2013)

(17) S. Yin, K.J. Tseng, C.F. Tong, R. Simanjorang, C.J. Gajanayake, and A.K. Gupta: "A Novel Gate Assisted Circuit to Reduce Switching Loss and Eliminate Shoot-through in SiC Half Bridge Configuration", in Proc. APEC2016, Long Beach, US (2016)

(18) Q. Zhou and F. Gao: "A Gate Driver of SiC MOSFET for Suppressing the Negative Voltage Spikes in a Bridge Circuit", in Proc. APEC2016, Long Beach, US (2016)

(19) Z. Zhang, F. Wang, L.M. Tolbert, and B.J. Blalock: "Active Gate Driver for Crosstalk Suppression of SiC Devices in a Phase-Leg Configuration", IEEE Trans. on Power Electronics, Vol.29, No.4, pp.1986-1996 (2014)

(20) P. Nayak and K. Hatua: "Active Gate Driving Technique for a $1200 \mathrm{~V} \mathrm{SiC}$ MOSFET to Minimize Detrimental Effects of Parasitic Inductance in the Converter Layout", in Proc. IEEE 2016 Energy Conversion Congress \& Expo (ECCE2016), Milwaukee (2016)

(21) H. Huang, X. Yang, Y. Wen, and Z. Long: "A Switching Suppression Scheme of SiC MOSFET by Active Gate Drive", in Proc. IPEMC2016- ECCE Asia, Hefei, China (2016) 
(22) H. Riazmontazer, A. Rahnamaee, A. Mojab, S. Mehrnami, S.K. Mazumder, and M. Zefran: "Closed-Loop Control of Switching Transition of SiC MOSFETs", in Proc. APEC2015, Charlotte, US (2015)

(23) K. Miyazaki, S. Abe, M. Tsukuda, I. Omura, K. Wada M. Takamiya, and T. Sakurai: "General-Purpose Clocked Gate Driver (CGD) IC with Programmable 63-Level Drivability to Reduce Ic Overshoot and Switching Loss of Various Power Transistors", in Proc. APEC2016, Long Beach, US (2016)

(24) H.C.P. Dymond, D. Liu, J. Wang, J.J. O. Dalton, N. Macneill, D. Pamunuwa, S.J. Hollis, and B.H. Stark: "Reduction of oscillations in a $\mathrm{GaN}$ bridge leg using active gate driving with sub-n resolution, arbitrary gateresistance patterns", in Proc. IEEE 2016 Energy Conversion Congress \& Expo (ECCE2016), Milwaukee (2016)

(25) K. Yamaguchi, Y. Sasaki, and T. Imakubo: "Low Loss and Low Noise Gate Driver for SiC-MOSFET with Gate Boost Circuit", in Proc. IECON 201440th Annual Conference of the IEEE, Dallas, pp.1594-1598 (2014)

(26) K. Yamaguchi, K. Katsura, T. Yamada, and Y. Sato: "Comprehensive Evaluation of Gate Boost Driver for SiC-MOSFETs", in Proc. IEEE 2016 Energy Conversion Congress \& Expo (ECCE2016), Milwaukee (2016)

Koji Yamaguchi (Member) received the B.S. and M.S. degree in

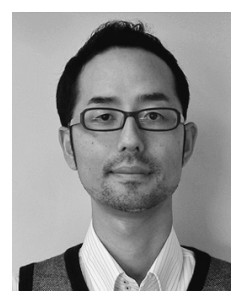
electrical engineering from Chiba University, Chiba, Japan, in 2000 and 2002 respectively. He is currently working toward the Ph.D. in Chiba University. From 2002 to 2006, he had developed power electronics systems for HEV's and EV's for Hitachi Ltd., Ibaraki, Japan. Since 2010, he has worked as a research associate for IHI Corporation. His main research interests are high power density power electronics and gate drivers for power devices. He is a P.E. Jp (Electrical \& Electronics Engineering), a member of IEEE and a member of IEEJ.

Kenshiro Katsura (Non-member) received the B.S. and M.S. degree

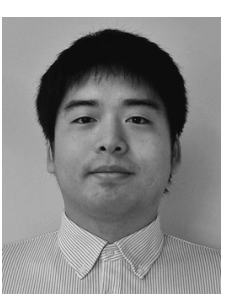
in mechanical, electrical and electronic engineering form Shimane University, Shimane, Japan in 2012 and 2014 respectively. Since 2014 , he has worked as a research associate for IHI Corporation. His main research interests are gate drivers for power transistors and high speed motor control.

Tatsuro Yamada (Non-member) has received the B.S. and M.S. de-

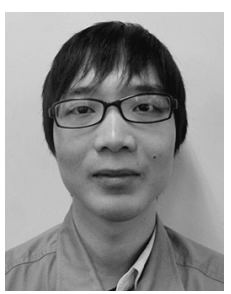
gree in Department of Adaptive Machine Systems from Osaka University, Osaka, Japan, in 2012 and 2014 respectively. Since 2015 , he has worked as a research associate for IHI Corporation. His main research interests are high power density power electronics and gate drivers for power devices.

Yukihiko Sato

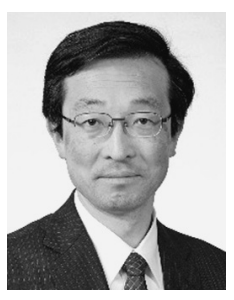

Japan.
Senior Member) (M'91) received the, B.Eng. M.Eng. and D.Eng. Degrees from Tokyo Institute of Technology in 1986, 1988, 1995, respectively. From 1988 to 2001, he has been with Tokyo Institute of Technology as a Research Associate and Associate Professor. From 2001, he has been with Chiba University, currently as a Professor and the Dean of Graduate School of Engineering. His current research interest includes control and circuit topology of power converters. He is a member of IEEE and a senior member of IEE of 